\title{
Miradas e instrumentos para la catalogación de paisajes latinoamericanos. Perspectivas emergentes
}

Gazes and tools for cataloging Latin American landscapes. Emerging perspectives

Gabriela Pastor, Manoel Rodrigues Alves, Domingo Sánchez Fuentes, Franco Marchionni, Laura Torres

\section{Filiación}

CONICET/Universidad Nacional de Cuyo, Universidade de São Paulo, Universidad de Sevilla, CONICET/Universidad de Mendoza, CONICET/Universidad Nacional de Cuyo

E mail: gpastor@mendoza-conicet.gob.ar, mra@sc.usp.br, dsanchez@us.es, fmarchionni@mendozaconicet.gob.ar, Itorres@mendoza-conicet.gob.ar

Primera versión recibida en: 03 de marzo, 2016

Última versión recibida en: 07 de junio, 2016

\section{Resumen}

El trabajo explora y discute herramientas teóricas e instrumentales asociadas a la producción de paisajes latinoamericanos desde la perspectiva del trabajo en red. El análisis se enfoca en tensionar los actuales instrumentos derivados de las normativas internacionales con argumentos centrados en elementos y dimensiones que los explican y dan sentido.

Desde una mirada que pone énfasis en las relaciones sociales como agente territorializador, se describen las nociones de paisaje subyacentes, así como las perspectivas teóricas que sostienen algunas de las instrumentaciones para aprehender y reconocer qué paisajes hemos producido y estamos produciendo socialmente. Más que presentar un trabajo acabado en sí mismo, se trata de compartir el proceso de algunas líneas de trabajo que convergen en el seno de un grupo de investigación en formación, la Red Interuniversitaria de Paisajes Latinoamericanos (RIPLa).

En primer lugar, se analizan los documentos internacionales que guían el debate en los procesos de construcción de instrumentos en el contexto latinoamericano, para luego exponer tres ejes argumentales que anidan en la RIPLA y que aportan miradas diferenciales hacia el paisaje. Finalmente se reconocen acuerdos, discrepancias desafíos y oportunidades para la producción de conocimiento en el marco del trabajo en red.

\section{Palabras Clave}

Paisajes Latinoamericanos; Redes de Conocimiento; Instrumentos; Perspectivas Emergentes

\begin{abstract}
The paper explores and discusses theoretical and instrumental tools associated with the production of Latin American landscapes from the perspective of networking. The analysis emphases on stressing current international instruments with arguments focused on elements and dimensions that explain and make sense on them.

From a glaze that emphasizes social relations as territorializing agent, the document describes the theoretical perspectives that support the design of the instruments to apprehend and recognize the social production of landscapes. Rather than a finished work itself, is explored some of the converging work lines within a research group in training, the Inter-University Network of Latin American Landscapes (RIPLA)

In the first part, the paper presents the analysis of the of instruments construction process in the Latin American context. Then, three research lines that converge in the RIPLA landscapes approach are exposed. Finally, it addresses the agreements, discrepancies, challenges and opportunities for the knowledge production in the framework of cooperative work in net-
\end{abstract}

\section{Keywords}

Latin American Landscapes; Knowledge Net; Tools; Emerging Perspectives 


\section{Sumario}

\section{Introducción}

1 El Marco Teórico: El paisaje entre la noción y la acción

2 La RIPLa, interrogantes y nuevas búsquedas

2.1 Estado del arte en algunas conceptualizaciones de/los paisaje(s), en una conjugación de espacio con sus actores sociales.

3 Resultados: Tres miradas

3.1 Mirada 1: el paisaje, la ciudad y la cultura

3.2 Mirada 2: el paisaje y el territorio en la gestión social del hábitat

3.3 Mirada 3: De patrimonios y paisajes: sujetos y objetos en la (re)producción del espacio

4 Discusión y Reflexiones finales en proceso: desplazamientos e incertidumbres

Bibliografía

\section{I ntroducción}

Algunos geógrafos comprenden a la noción de paisaje como uno de los aportes más importantes a la ciencia que la geografía ha podido brindar. Martínez de Pisón (1997) afirma que:

"entre los diversos conceptos y técnicas de trabajo que los geógrafos han construido y aplicado a su oficio, hay una concepción sobresaliente...que es la de paisaje" y que su "restitución intelectual plena sólo se consigue con un tratamiento abarcador...que no necesita desbordar los límites de la geografía" (194-195).

Señala además que la contribución al conocimiento del medio ambiente estaría dada desde el concepto de paisaje por una propuesta instrumental geográfica, sin menoscabar las contribuciones, aunque "parciales" de otras partes del conjunto. Sin embargo, las miradas transdisciplinares y particularmente desde la cultura, no han dejado de crecer y han hecho suyas tanto el concepto como el objeto paisaje, en un afán por comprender múltiples aspectos del hábitat humano. En ese ensanche de la noción las perspectivas son múltiples, tanto teóricas, escalares, de recortes espaciales o epocales; también referidas a los métodos y técnicas e instrumentos para reconocer y caracterizar el objeto de estudio. Es por ello que el paisaje se presenta como un campo de indagación permanentemente renovado que puede resultar inconmensurable, incluso, inasible.

En virtud de la relevancia que ha ido cobrando como objeto de indagación científica, el paisaje se ha visto interpelado como objeto de gestión, conservación, ordenación en cierta medida, impulsado por las transformaciones que las economías y dinámicas sociales proponen. En este marco y con el fin de favorecer consensos, se han redactado numerosos documentos que aunque de alcance diverso- han procurado homologar conceptos y categorías de análisis al mismo tiempo que también se han creado instrumentos tanto para la recolección de datos como para la definición de acciones e intervenciones. Siendo el ámbito europeo unos de los principales impulsores de la investigación e incorporación del paisaje como objeto de estudio y gestión, es relevante y significativa la bibliografía producida, así como la casuística que ha sido estudiada en ese espacio. 
De allí, que desde una perspectiva extra-geográfica este trabajo se propone poner en tensión las perspectivas que nutren las líneas de trabajo que convergen en la incipiente Red Interuniversitaria de Paisajes Latinoamericanos ${ }^{1}$ (RIPLa); una red que surge justamente como espacio de indagación y construcción de conocimiento a partir de los interrogantes que se desprenden de las convenciones de paisaje e instrumentos emanados de las mismas. Las propias diversidades de los grupos e instituciones participantes articulan las fortalezas y oportunidades sobre las que la red propone aproximarse a esos desafíos. Es que teniendo en cuenta que, tanto los inventarios como los catálogos constituyen insumos de conocimiento para la gestión del paisaje estrechamente articulados al ordenamiento territorial, sería esperable que estas herramientas reunieran y conciliaran los saberes expertos $y$, los conocimientos y valoraciones sociales que expresan tanto los paisajes como sus elementos componentes.

El análisis se centra entonces, en la revisión de los catálogos de paisajes que son explorados a partir de una perspectiva que sobre imprime lo local, complejo y heterogéneo por encima de la esteticidad como condición. En otras palabras, se pretende indagar si estos instrumentos teóricos y operativos resultan de utilidad para comprender la lógica de producción y transformación de los paisajes en el contexto latinoamericano.

Para ello se parte del análisis de un conjunto de documentos elaborados en el marco de distintos acuerdos y escalas de consenso para la identificación y reconocimiento de paisajes. Luego se exponen los fundamentos teóricos que soportan la creación de la RIPLA para luego reconocer tres ejes argumentales que aportan miradas diferenciales teóricas y escalares hacia el paisaje. Finalmente se reconocen los acuerdos, ciertas discrepancias y se señalan algunos de los desafíos y oportunidades para la producción de conocimiento en el marco del trabajo en red.

\section{EI Marco Teórico: El paisaje entre la noción y la acción}

Este apartado recupera el derrotero de la noción de paisaje y el desarrollo de las acciones en torno de él desde 1992 a la fecha, a través de la consideración de algunos documentos internacionales claves sobre la materia. Así se han revisado los emanados de UNESCO (1992- 2002), del Council of Europe-CEP (2000), otros producidos en Gran Bretaña (Countryside Agency and Scottish Natural Heritage, 2002 + Lambrick, George et al, 2013), el formulado por la LALI -Latin American Landscape Initiative- (2012), la Carta I beroamericana del Paisaje Cultural (CIPC-2012) y la Declaración de Santiago de Cuba sobre los paisajes culturales del Caribe (2005). Esta ajustada compilación no tiene la intención de actuar como una guía técnica con todos los detalles de la hermenéutica, la metodología y los estudios de caso en la aplicación de las normas emanadas de estos documentos, simplemente permite ponderar la riqueza de la noción y su amplia gama de aplicaciones y escalas de estudio, aunque

La Convención de Patrimonio de la Humanidad (1992) constituyó el primer instrumento legal internacional para el reconocimiento y la protección de los paisajes culturales. Allí se reconoció que los paisajes culturales representaban las "obras combinadas de la naturaleza y el hombre" y eran ilustrativas de la evolución de la sociedad y los asentamientos humanos a través del tiempo, bajo la influencia de las restricciones físicas y/o las oportunidades que brindaba su entorno natural y las sucesivas fuerzas sociales, económicas y culturales, tanto internas como externas. Se señalaba que el "paisaje cultural" abarcaba una diversidad de manifestaciones de la interacción entre el hombre y su medio ambiente natural y reflejaban con frecuencia, técnicas específicas de uso sostenible de la tierra, así como una relación espiritual específica con la naturaleza. Señalaba además que la protección de los paisajes culturales podría

1 Red conformada por investigadores de universidades y centros de investigación de Argentina, Brasil, México y España 
contribuir a las técnicas modernas de uso sostenible de la tierra y podría también, mantener o incrementar los valores naturales del paisaje. (Rìos, M., Rössler, M., Lepeigné-Cobo, A. M., 2000).

En el año 2000 se firma el Convenio Europeo del Paisaje cuyo objetivo principal fue la promoción de la protección, gestión y ordenación de los paisajes europeos y la organización de la cooperación en ese ámbito. El texto acordó señalar que: entenderá por «paisaje» cualquier parte del territorio tal como lo percibe la población, cuyo carácter sea el resultado de la acción y la interacción de factores naturales y/o humanos. El mismo documento se centró en marcar las líneas maestras sobre las que deberían arbitrarse determinadas prácticas comunes que afectarían, sobre todo, a los distintos mecanismos de actuación sobre el paisaje (Jiménez Olivencia, 2008). Sin dudas este convenio contribuyó notablemente a señalar la relevancia del paisaje promoviendo numerosas articulaciones intra y extra europeas. (Aldred, O. and Fairclough, G., 2003; Bertrand, G., 2008; Caballero Sánchez, J uan Vicente, 2012; Clarke J., Darlington J. \& Fairclough G. (eds), 2003; Paniza Cabrera, A., 2008; Sabaté Bel, J., Vera Galván, J., 2008; y en América Latina entre tantos otros: Pastor et al, 2014; Ferrari, M., Paterlini de Koch, O., 2013).

Un señalamiento especial merecen los aportes realizados desde Gran Bretaña (Fairclough, G. (ed.) 1999; Fairclough, G.J., Lambrick, G. and McNab, A. (eds.) 1999; Swanwick, 2002 para la Countryside Agency and Scottish Natural Heritage; English Heritage and Cornwall County Council, 2008 y desde Irlanda: Lambrick, George, Jill Hind and Ianto Wain, 2013). Estos trabajos convienen en apuntar que el término paisaje refiere a la relación entre las personas y el lugar desde donde formulan algunas directrices a transitar por los responsables de la construcción y/o preservación del paisaje para la toma de "decisiones informadas".

De este lado del Atlántico y a partir del año 2012 surge bajo el nombre de LALI - la Iniciativa Latinoamericana del Paisaje (por las iniciales de su nombre en inglés)

En sintonía con los acuerdos que la precedieron, la LALI propone, convenir políticas binacionales y multinacionales en materia de conservación, protección, manejo y recuperación de unidades de paisaje ubicadas en zonas transfronterizas. Como fin se plantea allanar el camino para lograr una Convención Internacional del Paisaje.

Otro de los documentos de relevancia lo constituye la Carta Iberoamericana del Paisaje Cultural (CIPC) cuyas recomendaciones cristalizaron en un encuentro en Cartagena de Indias en noviembre de 2012. Este documento persigue la unificación de criterios para la identificación, reconocimiento, protección y formulación de metodologías de actuación sobre el patrimonio paisajístico. Asimismo, considera la dimensión histórica y los rasgos distintivos como fundamento de su salvaguarda y fortalecimiento.

Pero previamente a la LALI y la CIPC, en noviembre del 2005 se había realizado en Santiago de Cuba, la Reunión de Expertos sobre los "Paisajes Culturales en el Caribe: Estrategias de Identificación y Salvaguardia" con el apoyo de UNESCO. La reunión fue motivada del reconocimiento de especial atención que el paisaje del Caribe requería por tratarse de una de las subregiones que menos representatividad alcanzaba en la Lista de Patrimonio Mundial. Amparados en la noción de paisaje acuñada por la Convención del Patrimonio Mundial de 1992, la Declaración de Santiago de Cuba recomendaba el establecimiento de objetivos estratégicos que persiguieran la credibilidad, la conservación y la capacidad de asegurar que los paisajes culturales se insertaran dentro de las políticas nacionales y locales de desarrollo, así como en la planificación física de los territorios. Complementariamente, proponía el fomento de campañas sistemáticas destinadas a promover la comprensión de los valores materiales e inmateriales, así como la diversidad biológica y cultural de los paisajes culturales caribeños prestando particular atención a los jóvenes y niños, a la mujer y a la familia. 


\begin{tabular}{|c|c|c|c|}
\hline $\begin{array}{l}\text { Documentos } \\
\text { Internacionales }\end{array}$ & Año/s & Definiciones/Aportes & Autores/Casos \\
\hline \multicolumn{4}{|c|}{ Aportes del lado este del Atlántico } \\
\hline UNESCO & $\begin{array}{l}1992- \\
2002\end{array}$ & $\begin{array}{l}\text { Reconoció que los paisajes culturales representaban las "obras } \\
\text { combinadas de la naturaleza y el hombre" ilustrativas de la evolución } \\
\text { de la sociedad y los asentamientos humanos a través del tiempo, bajo } \\
\text { la influencia de las restricciones físicas y/o las oportunidades que } \\
\text { brindaba su entorno natural y las sucesivas } \\
\text { fuerzas sociales, económicas y culturales, tanto internas como } \\
\text { externas. }\end{array}$ & $\begin{array}{l}\text { Rìos, M., Rössler, M., Lepeigné- } \\
\text { Cobo, A. M., } 2000\end{array}$ \\
\hline $\begin{array}{l}\text { Council of Europe- } \\
\text { CEP }\end{array}$ & 2000 & $\begin{array}{l}\text { Define «paisaje» como cualquier parte del territorio tal como lo } \\
\text { percibe la población, cuyo carácter sea el resultado de la acción y la } \\
\text { interacción de factores naturales y/o humanos. }\end{array}$ & $\begin{array}{l}\text { (Aldred, O. and Fairclough, G., } \\
\text { 2003; Bertrand, G., 2008; } \\
\text { Caballero Sánchez, Juan Vicente, } \\
\text { 2012; Clarke J., Darlington J. } \\
\text { \&Fairclough G. (eds), 2003; } \\
\text { Paniza Cabrera, A., 2008; Sabaté } \\
\text { Bel, J., Vera Galván, J., 2008; y } \\
\text { en América Latina entre tantos } \\
\text { otros: Pastor et al, 2014; Ferrari, } \\
\text { M., Paterlini de Koch, O., 2013). }\end{array}$ \\
\hline $\begin{array}{l}\text { Gran Bretaña } \\
\text { (Countryside } \\
\text { Agency and Scottish } \\
\text { Natural } \\
\text { Heritage+Lambrick, } \\
\text { George et al,) }\end{array}$ & $\begin{array}{l}2002- \\
2013\end{array}$ & $\begin{array}{l}\text { Paisaje como relación entre las personas y el lugar. Consolida las } \\
\text { ideas más recientes sobre el tema y argumenta directrices para la } \\
\text { toma de "decisiones informadas" en la construcción y/o preservación } \\
\text { del paisaje. }\end{array}$ & $\begin{array}{l}\text { Fairclough, G. (ed.) 1999; } \\
\text { Fairclough, G.J., Lambrick, G. } \\
\text { and McNab, A. (eds.) 1999; } \\
\text { Swanwick, 2002 para la } \\
\text { Countryside Agency and Scottish } \\
\text { Natural Heritage,; English } \\
\text { Heritage and Cornwall County } \\
\text { Council, 2008 y desde Irlanda: } \\
\text { Lambrick, George, Jill Hind and } \\
\text { Ianto Wain, 2013. }\end{array}$ \\
\hline $\begin{array}{l}\text { LALI } \\
\text { American } \\
\text { Landscape } \\
\text { Initiative- }\end{array}$ & 2012 & $\begin{array}{l}\text { Define al paisaje: “...como un espacio/tiempo resultado de factores } \\
\text { naturales y humanos, tangibles e intangibles, que al ser percibido y } \\
\text { modelado por la gente, refleja la diversidad de las culturas” al que } \\
\text { reconoce como: recurso, crisol del intangible de las comunidades } \\
\text { latinoamericanas, bien, valor y derecho }\end{array}$ & $\begin{array}{l}\text { Persigue la unificación de } \\
\text { criterios para la identificación, } \\
\text { reconocimiento, protección y } \\
\text { formulación de metodologías de } \\
\text { actuación sobre el patrimonio } \\
\text { paisajístico. }\end{array}$ \\
\hline $\begin{array}{l}\text { Carta } \\
\text { Iberoamericana del } \\
\text { Paisaje Cultural } \\
\text { (CIPC-2012) }\end{array}$ & 2012 & $\begin{array}{l}\text { Caracteriza al paisaje como: } \\
\text { "el resultado de la interacción del ser humano sobre el medio natural, } \\
\text { las huellas de sus acciones en un territorio cuya expresión es } \\
\text { percibida y valorada por sus cualidades específicas y, por ser soporte } \\
\text { de la memoria y la identidad de una comunidad. Todo territorio que } \\
\text { cuenta con cualidades estéticas e históricas debe ser considerado } \\
\text { como paisaje cultural y no tan solo como sitios que requieren de } \\
\text { atención por su vulnerabilidad". }\end{array}$ & $\begin{array}{l}\text { Precisa las acciones conducentes } \\
\text { a garantizar una buena gestión del } \\
\text { paisaje cultural considerando } \\
\text { cinco aspectos fundamentales. }\end{array}$ \\
\hline $\begin{array}{lr}\text { Declaración } & \text { de } \\
\text { Santiago de } & \text { Cuba } \\
\text { sobre los } & \text { paisajes } \\
\text { culturales } & \text { del } \\
\text { Caribe. }\end{array}$ & 2005 & $\begin{array}{l}\text { Amparados en la noción de paisaje acuñada por la Convención del } \\
\text { Patrimonio Mundial de 1992, la Declaración de Santiago de Cuba } \\
\text { recomendó el establecimiento de objetivos estratégicos que } \\
\text { persiguieran la credibilidad, la conservación, la capacidad de } \\
\text { asegurar que los paisajes culturales se inserten dentro de las políticas } \\
\text { nacionales y locales de desarrollo así como en la planificación física } \\
\text { de los territorios. }\end{array}$ & $\begin{array}{l}\text { No resulta taxativa en la } \\
\text { indicación de instrumentos, pero } \\
\text { sugiere la realización de } \\
\text { inventarios subregionales } \\
\text { preliminares de paisajes } \\
\text { culturales ubicados en los } \\
\text { territorios de los Estados partes y } \\
\text { un conjunto de medidas } \\
\text { tendientes a fortalecer el espacio } \\
\text { formativo y de producción de } \\
\text { información específica }\end{array}$ \\
\hline
\end{tabular}


Apenas dos años más tarde de la Convención de 1992, el Comité de Patrimonio Mundial de la UNESCO, lanzó una estrategia global para la conformación de una lista representativa del patrimonio mundial garantizando la inclusión de la diversidad cultural y natural de valores universales excepcionales en el mundo. No fue sino hasta 2002, cuando esa estrategia global se materializó en la definición de cuatro objetivos estratégicos, conocidos como las 4 " $C$ " (Credibilidad, Conservación, Capacidad y Comunicación) enunciados por el Comité en Budapest 2002, convirtiéndose en objetivos instrumentales para la formulación de planes de acción para América Latina y el Caribe a partir del 2004.

Desde la firma del Convenio de Florencia (CEP, 2000) se han promovido en el ámbito europeo, la aprobación de leyes específicas de paisaje, la creación de direcciones generales redacción de planes de ordenación del paisaje, así como desarrollado un cúmulo significativo de reuniones que permitieran alcanzar los postulados del convenio. Los aportes hechos desde Gran Bretaña y contenidos en el documento Landscape Character Assessment fruto de colaboración entre The Countryside Agency y la Scottish Natural Heritage y aquellos provenientes desde Irlanda y condensados en Historic Landscape Characterisation in Ireland: best practice guidance se constituyeron en los antecedentes directos para que el Observatorio del Paisaje de Catalunya (www.catpaisatje.net) encarara la redacción de los catálogos de paisaje en acuerdo con las recomendaciones del CEP.

Por su parte, la puesta en marcha de LALI propuso algunos instrumentos a desarrollar como: planes, estudios de paisaje e integración, desarrollo de códigos profesionales y especialmente la realización de inventarios, catálogos y cartas de paisaje multiescalares con el fuerte aval de asociaciones mundiales como la IFLA y sus miembros regionales.

Por otro lado, la Carta Iberoamericana del Paisaje Cultural (CIPC) precisa las acciones conducentes a garantizar una buena gestión del paisaje cultural considerando cinco aspectos fundamentales: el documental, que implica la realización de estudios rigurosos por parte de especialistas en recursos patrimoniales, el impacto de los proyectos (físico y social) que reasegura la repartición equitativa y ética de los beneficios que otorguen los proyectos, el participativo que persigue el diseño de instrumentos que apuesten a la participación comunitaria en el marco de una política de innovación pública, a través del uso de las TIC; se señala además la urgencia de abordar el tema del paisaje desde el criterio de sostenibilidad involucrando aspectos relacionados con la cualificación de los paisajes para evitar su rápido deterioro, que por su fragilidad y difícil recuperación son altamente vulnerables y finalmente la difusión como instrumento adecuado para incentivar la divulgación de los valores patrimoniales de los paisajes culturales y así mejorar la conciencia de la comunidad sobre los beneficios sociales, económicos y ambientales de su salvaguardia.

Por último, la Declaración de Santiago de Cuba sobre los Paisajes Culturales en el Caribe no resulta taxativa en la indicación de instrumentos, pero sugiere la realización de inventarios subregionales preliminares de paisajes culturales ubicados en los territorios de los Estados partes y un conjunto de medidas tendientes a fortalecer el espacio formativo y de producción de información específica

En síntesis, las nociones de paisajes que sustentan estos acuerdos presentan características comunes al tiempo que reconocen matices diferenciales que resultan significativos al momento de intentar instrumentar las recomendaciones. Entre ellas, la perspectiva del paisaje como objeto, presente en la definición acuñada por UNESCO y retomada por la CIPC. Tanto la LALI como el CEP plantean una definición conceptual que involucra a las comunidades relacionadas 
con ese patrimonio, estableciendo una suerte de definición tripartita en la que convergen lo natural y lo humano de su constitución pasada y las valoraciones que sobre esas construcciones recaen en el presente y se proyectan hacia el futuro a partir de la percepción de ese producto cultural. Otra característica a destacar es que tanto LALI (2012) como el CEP (2000) consideran paisaje a la integridad del territorio, incluyendo los paisajes "ordinarios" o de la vida cotidiana, las perspectivas de UNESCO se circunscriben a los singulares, excepcionales (UNESCO, 1992) y a los territorios de valor histórico y/o estéticos como condiciones excluyentes para su designación como paisajes culturales según la CI PC (2005).

En cuanto a las herramientas para el conocimiento de los paisajes, es generalizada la recomendación de proceder en la línea de los inventarios y catalogaciones, en la redacción de cartas o instrumentos de consensos para llevar adelante acciones más participativas, aunque permanece abierto el espacio para el desarrollo de esos instrumentos.

\section{La RI PLa, interrogantes y nuevas búsquedas}

El conjunto de antecedentes descriptos, indujeron a la creación de la RIPLA como espacio para la construcción de conocimiento desde los ámbitos académicos. Se trata de una red que surge de reconocer que las indagaciones sobre el paisaje construido suelen emerger, bien como producto residual de las acciones en los diversos campos vinculados a la construcción del hábitat o bien, traccionada por las demandas de intervenciones más inspiradas en cuestiones asociadas a la conservación de elementos conspicuos - naturales o culturales- de algunos paisajes que por comprender las territorializaciones que devienen en transformaciones de los paisajes. La RIPLa se propuso abordar ese espacio de vacancia para desarrollar nuevos conocimientos que aporten tanto a la formación académica como a la elaboración de instrumentos que, desde una mejor comprensión del paisaje y el territorio como patrimonios de la diversidad, contribuyeran a optimizar la orientación de las acciones acorde a los desafíos que las nuevas territorialidades de América Latina proponen en un marco de sostenibilidad y equidad.

\subsection{Estado del arte en algunas conceptualizaciones de/ los paisaje(s), en una conjugación de espacio con sus actores sociales.}

Nogué (2008:10-11) reconoce al paisaje como la "proyección cultural de una sociedad en un espacio determinado [...] dinámico código de símbolos que nos habla de la cultura, de su pasado, de su presente y también de su futuro". Esta afirmación retoma lo señalado por Santos (1996: 42) cuando apunta que el paisaje no es para siempre, sino que es resultado de sumas y restas, a veces sucesivas, otras, de forma simultánea. Aliata y Silvestri (1994) señalan que el paisaje siempre ha estado presente como representación de la naturaleza, pero también como comprensión patrimonial del territorio (Pastor et al, 2014) o como valoración de los productos del trabajo humano que, en territorios de condición periférica (Hiernaux y Lindón, 2004) explican con mayor énfasis las dinámicas de los procesos, actores y sus improntas territoriales.

Las categorías, aportes y articulaciones propuestas por estos autores ayudaron a consolidar el posicionamiento epistemológico y metodológico de la RIPLa para afrontar el desafío que supone la búsqueda de una mirada innovadora para conocer y eventualmente catalogar paisajes latinoamericanos.

Sin embargo, el lugar adoptado, aquel de pensar en los instrumentos de catalogación de paisajes desde una perspectiva emergente, no nos exime de sospechar de nuestros pasos. La crítica de la sospecha recuerda que todos los valores universales son «valores particulares 
universalizados» y sospechosos en virtud de que la cultura universal es la de los dominantes (Bourdieu, P., 1994: 128).

Entonces con el objetivo de reparar en algunas conceptualizaciones, la presente labor deja de lado el estudio de aquella versión absoluta del espacio aportada por las ciencias físicas a la geografía para darle importancia al estudio de la espacialidad -y con él, al paisaje- de los fenómenos sociales. En esta dirección consideramos lícito extrapolar al paisaje, aquello señalado por David Harvey (1969):

"el simplista punto de vista del espacio entendido como contenedor, no puede ser aceptado", pues limitarse al estricto concepto absolutista sería omitir otros elementos que sabemos que lo conforman (Avendaño Flores, I. 2010:14).

Desde la perspectiva geográfica, la territorialidad se define como la acción de significar un lugar y con ello, marcar, generar y alterar el territorio mediante hábitos, ritos, costumbres, prácticas y usos por un sujeto individual o colectivo. Frente a este panorama Harvey nos llama a resinificar, redefinir y valorizar un espacio "propio" y con ello a pensar en nuestros paisajes (Harvey, [1990] 2004: 240).

En esa misma línea Bauman nos interpela para reconocer la Identidad de pertenencia territorial de nuestros paisajes. Nos habla del apego que los sujetos tienen a la tierra, al territorio y al paisaje (Bauman, 2005: 47). También nos habla de otras relaciones como la pertenenciaidentidad. Desde la vertiente sociológica, el concepto de identidad es polifacético. En general, denota lo que las personas se hacen sobre quiénes son y lo que tiene sentido para ellas. (Bauman, 2001; 2002; 2005 y Hall, 2003). Para los autores recién mencionados, la identidad se ancla tanto en pertenencias como en identificaciones.

Otro de los autores considerados, Doreen Massey (2005) al enfrentarnos con el estudio del territorio y del paisaje nos invita a un cambio de escalas, a mirar lo local, lo translocal y lo nacional cuando pensamos en nuestros paisajes. Emerge reveladora cuando sugiere una coconstrucción del espacio social como sujetos activos y con ello paisajes genuinos como imagen de esos procesos (Massey, D., 2006).

Pero todas estas búsquedas, ideas y valores no pueden ser considerados y aplicados al estudio de nuestros paisajes sin un procedimiento claro. Para ello valoramos los aportes de la teoría crítica expuesta por Habermas como una forma "otra" de reflexionar sobre objetos y fenómenos provenientes de las ciencias sociales. Aquí se rescata el enfoque histórico hermenéutico que considera la explicación del mundo desde las relaciones del lenguaje, la tradición y la historia; y el principio de etnografía reflexiva expuesto por Hammersley y Atkinson (1994):

«Un objeto de investigación es un fenómeno visto desde un ángulo teórico específico», pues «a determinadas características no se les presta atención e, incluso, el fenómeno considerado no se agota completamente en la investigación». Si extrapolamos estos postulados al paisaje como objeto de estudio, podemos pensar en que éste, puede ser interpelado por el conjunto de preguntas que se considera significativo dirigirle; un conjunto de preguntas que delimita el ámbito de lo observable y de lo no observable, que siempre se hacen desde una perspectiva teórica concreta que generalmente es equiparable a la 'cultura' ([1994 (1983): 57] En: Jociles Rubio, M., 1999: 04).

Nuestro interés es presentar una posición mediadora de todas estas teorías cualitativas y ofrecer una propuesta de diseño metodológico para abordar estudios relacionados con las ciencias sociales. Estas miradas intentan funcionar como claves o categorías "otras" con las cuales es preciso calibrar nuestros instrumentos. 
Para ello merece detenerse en el análisis de la literatura latinoamericana proveniente del campo del ordenamiento y/o de la planificación del territorio. Allí se dan cuentas de las adscripciones teóricas y aproximaciones operativas que, en gran sintonía con lo expuesto en apartados anteriores caracterizan el estado del conocimiento del paisaje en estos contextos. Los autores coinciden en señalar que el estudio del paisaje latinoamericano está pendiente de ser abordado científicamente a pesar de que “...todavía conforma un material fácilmente reconocible e identificable" (Martignoni, 2008: 12)

Sin ánimo de exhaustividad se pueden señalar al menos dos grandes encuadres: uno que anclada en el análisis del binomio sociedad-naturaleza, que focaliza su campo de atención en el territorio (Pérez Bustamante y Parra Ponce, 2004) y prioriza algunas figuras para la gestión, ordenación de los paisajes existentes, así como la creación de otros nuevos (Etulain y López, 2010). El otro que revisa el paisaje como cualidad de lo urbano (Maderuelo, 2010). Estas aproximaciones -en clara consistencia con los postulados de la Carta de Florencia (Convenio Europeo del Paisaje, 2000)- promueven catálogos e inventarios como instrumentos para la recolección y análisis de los paisajes como datos para la ordenación del territorio (Bertuzzi, 2009); también recurren con bastante énfasis a la figura de los parques patrimoniales como elemento de gestión (Pérez Bustamante y Parra Ponce, 2004). Éstos últimos, resultan herederos de las figuras instituidas por el National Park Service (NPS, 2002) que algunos autores reconocen como referentes del nuevo paradigma de la relación naturaleza- cultura para el ordenamiento territorial del siglo XXI (Pérez Bustamente y Parra Ponce, 2004;

Otra de las perspectivas dominantes es la referida a los paisajes urbanos que Campos Reyes (2003) asocia a los artificiales, en clara confrontación con los paisajes rurales como representación de la naturaleza. Este autor reconoce a los espacios libres (espacio público y espacio residual) como el lugar para las oportunidades de repensar las articulaciones globallocal, así como las dimensiones simbólicas del paisaje propio.

Pero más allá de estas aproximaciones, el análisis de la bibliografía confirma una vez más, que los documentos de consenso para la toma de decisiones respecto del paisaje elaborados por los países del norte han sido útiles no sólo para su propio contexto de enunciación, sino que han ejercido una notable influencia en Latinoamérica. Las cartas, catálogos e inventarios de paisaje han sido objeto propositivo de distintas convenciones tanto regionales como nacionales que, con matices, reconocen las referencias a los modelos de gestión del territorio emanados de aquellos contextos, de allí que también, aboguen por la elaboración de los mismos instrumentos.

\section{Resultados: Tres miradas}

A partir de las perspectivas enunciadas y frente a los consensos de carácter global de fuerte impacto en Latinoamérica, la RIPLa ha intentado buscar su espacio, construyendo una propuesta exploratoria articulada sobre tres conjunciones teórico-operativas que se presentan como pregnantes para la producción de conocimiento.

Por un lado, el abordaje desde la conjunción paisaje, ciudad y cultura desde cuya perspectiva se pone énfasis en la comprensión de las transformaciones espaciales, culturales y técnicas asociadas al contexto contemporaneidad de la ciudad, la cultura, e incluso, la propia noción del paisaje.

Un segundo posicionamiento focalizado en la paisaje y gestión social del hábitat perspectiva desde la que se procura indagar la capacidad mediadora del paisaje entre territorio y sociedad. Y una tercera matriz comprensiva paisaje y (re)producción del espacio que rescata la perspectiva lefebvriana que considera que todo espacio es socialmente producido porque cada 
modo de producción tiene una relación distinta hacia el espacio, produce su propio y único tipo de espacio y de allí su paisaje (Marchionni et al, 2014). Consecuentemente y amparados en los avances y aportaciones de las ciencias sociales, se reconocen diversas aproximaciones que pretenden contribuir a la riqueza de la noción paisaje e intentan superar la hibridez de su concepción, como también, a sus articulaciones con casuísticas que permitan abordar las complejidades de los paisajes de territorios periféricos. En este sentido se señalan tres miradas que, con carácter experimental, ensayan algunas reflexiones consecuentes con los posicionamientos expuestos.

\subsection{Mirada 1: el paisaje, la ciudad y la cultura}

Para Erwin Strauss el paisaje no es una categoría o experiencia antropológica -es pre-cultural, pre-antropológica- es el espacio del sentir a la vez que foco original de todo encuentro con el mundo. En este sentido, el espacio del paisaje es, desde el inicio, el lugar sin lugares del ser perdido. Por lo tanto, antes de la institución de cualquier experiencia visual, antes de cualquier espectáculo y dando al espectáculo su verdadera dimensión, el paisaje es expresión y más precisamente, expresión de la existencia (Besse, 2006: 93).

Para Besse, "la geografía o el paisaje no son nada más que el mundo de las mediaciones, o sea, la cultura, en el interior de las cuales la existencia adquiere un sentido concreto" (94). Usualmente, empleamos dos concepciones de paisaje: por un lado, el paisaje como sinónimo de la naturaleza, contemplada y dominada por el sujeto social (campo de las artes y la filosofía) y por otro, la noción de paisaje como sedimentación, como permanente interacción entre el medio natural y el medio humano (campo de la geografía y las cienciasambientales).

Sin embargo, también podemos apuntar que estas concepciones no contemplan plenamente la noción de paisaje en cuanto expresión de la existencia, de algo inconcluso que es propiamente una apertura de sentido y de historia. Más allá de eso, ¿observamos o habitamos paisajes?

El paisaje no es una escena que observamos: es el mundo en que vivimos. Por tanto, habitamos y conformamos paisajes en un presente de actualidad innegociable, de la infatigable urgencia de posibilidades que no se puede adelantar, de una ciudad coetánea que responde a parámetros propios de una época de transición. A pesar de la relación de experiencia y/o pertenencia al espacio urbano, persiste en medio de un conjunto de transformaciones en las dimensiones técnicas y tecnológicas; se observa una ciudad que emerge constituida por textualidades y morfologías inéditas que operan en un contexto sociocultural diferenciado conformando micro geografías de un cotidiano denso y de nuevas conformaciones de uso y apropiación del espacio - paisajes, espacialidades y territorialidades distintas-.

En un escenario de disolución de experiencias actuales, frecuentemente superficiales, elementales e inestables, los territorios de las representaciones se replican como accidentales, contaminados, contingentes, híbridos, mestizos, relativos, sincréticos. En este escenario, constituido por un conjunto de prácticas que se trasvasan más allá de sus campos y límites, se combinan nuevos patrones que conducen a la transformación del paisaje urbano en mercadería para consumo inmediato, un consumo condicionado por tres técnicas del capitalismo tardío: mutación, flujo y desorden. Paisajes en que las nuevas formas de relaciones sociales dan preferencia a ámbitos privados, además del aumento de la movilidad que valoriza más el flujo que la permanencia y por medio de la cual se constituyen nuevos sentidos de urbanidad. En este contexto, teniendo como premisa que el lugar se vincula de modo inexorable a la realización de la vida como condición y producto del establecimiento de las relaciones reales indispensables a ella, correspondiendo la expresión "el hombre habita lugares" nos preguntamos, ¿cuáles serían los desdoblamientos de las nuevas formas de "habitar" en la 
construcción de paisajes de la "ciudad urbanal" (Muñoz, 2008), de la ciudad desconectada del ser en el mundo?

Un paisaje urbano que demanda nuevos caminos de investigación. Caminos esos que, como argumenta Besse, no significan comprender el paisaje como una noción estética. Metodológicamente para Latour, la forma de abordar el problema del paisaje contemporáneo, o mejor, de la contemporaneidad de la noción de paisaje, no se constituye en el estado de la cuestión, sino en cuestiones de preocupación. Por tanto, proponemos la noción de hodología, una palabra nueva en el léxico del paisaje. Proviene del griego Hodos, que significa camino o jornada. Hodología es por tanto, la ciencia o estudio de los caminos.

La tesis fundamental de esta mirada e interpretación, de los mismos hechos que han perfilado una y otra vez las teorizaciones sobre el paisaje consistirá precisamente en la estimulación de algunas de esas claves, para que diluyan, o quizá se contenten con retrasar las imposiciones mediático-consumistas de las miradas, que sólo se constituyen como testimonio y convalidación de una experiencia homologada con anterioridad por los medios de comunicación (landscape branding) y ya es consustancial con nuestros hábitos. El éxtasis de esa experiencia, desdoblada, por no decir expropiada de la realidad, es una afección dislocada de los sentidos cuya única finalidad consiste en poder decir que se ha estado allí, y se ha sobrevivido. Aún en la imposibilidad de describir todo el campo de problematizaciones y ejemplos que agoten las hipótesis singularizaremos las especulaciones hasta condicionarlas a un marco más restringido como es la ciudad, lo urbano, también lo no urbano. Recorte que retomaremos en las reflexiones finales para proponer tres desplazamientos intentando reactivar la vitalidad del paisaje como argumento de nuestro tiempo y para la comprensión de los seres humanos ante sí.

\subsection{Mirada 2: el paisaje y el territorio en la gestión social del hábitat}

La hermenéutica originariamente es una disciplina que pretende interpretar y comprender los textos. Podemos registrar el recorrido significante de la hermenéutica desde Grecia hasta la tradición moderna de Swchleiermacher y Dilthey, pasando por la Ilustración y el Romanticismo, pero nos interesa destacar la hermenéutica ontológica, de principios del siglo XX de Heidegger, Gadamer, Habermas, y Ricoeur.

Heidegger considera que el entendimiento no es una actividad de la conciencia sino una condición de nuestro ser en el mundo. Sitúa el entendimiento como aquello que nos permite definir nuestro ser en el mundo. Las principales aportaciones de Gadamer (1960) están referidas a la necesidad de contar con el contexto y cuestionar la metodología en la interpretación de la verdad. Habermas, se interesó en la acción comunicativa, en entender los comportamientos de los grupos sociales de manera que la interpretación llega a convertirse en una comprensión escénica, y Ricoeur, introdujo la noción de símbolo, entendiendo el texto como una estructura cuadrimensional -forma, historicidad, recepción e interpretación- que requiere cuatro etapas de aproximación.

La hermenéutica se ha caracterizado por ser polimórfica y por reivindicar la necesidad de analizar el contexto. Para leer un texto es necesario conocer los códigos de escritura, la gramática y la poética que permiten entender lo que el autor quiere transmitir y, a la vez, interiorizar el mensaje y hacerlo parte del desarrollo vital del receptor.

A nuestro juicio los estudios territoriales, las lecturas que se hacen del territorio, se deberían abordar de la misma manera. Desde los tiempos antiguos los territorios se han leído de distintos modos. Las diferentes sociedades han ido dando diversas formas a sus territorios y han tenido disímiles maneras de observarlo, generando diferentes paisajes reflejo del momento histórico, de sus creencias, de sus olvidos. 
Ante la complejidad que adquieren los actuales procesos de territorialización, resulta necesario traducir a un código común los mensajes que aparecen en las distintas capas del territorio, escritas con signos muy diversos. Es imprescindible realizar una lectura transversal que permita un mejor acercamiento a una realidad de complejidad creciente. El escenario que se crea cuando se introduce la percepción en los estudios territoriales, cuando se incorpora el paisaje como noción, da pie a pensar de un modo alternativo los instrumentos de planificación para dar una respuesta, en clave de sostenibilidad, a los procesos de territorialización y urbanización, incorporando a la población en la toma de decisiones desde el origen del proceso.

Los estudios de paisaje pueden considerarse como un sistema cuasi-completo transdisciplinar de aproximación a estas realidades y un método de valoración y planificación de nuevas situaciones, desde el que se puede proteger, gestionar y ordenar. El territorio es el medio físico transformado por el hombre que alcanza la categoría de Paisaje cuando se incorpora la emoción. El concepto de Paisaje está íntimamente relacionado con la percepción que se tiene del territorio, y es con el que se identifica la población.

Si el Paisaje son múltiples miradas sobre un territorio formado por la interacción de distintas capas (ecológica, económica, social) y con distintos espesores según su dimensión en el tiempo, los estudios de paisaje, como proceso transdisciplinar, deberían abordar la transformación del soporte territorial, los aspectos sensoriales, su relación con los estéticos y emocionales y las interacciones dinámicas entre sus componentes (el paisaje como sistema geoecológico). Pero también debe atender al conjunto de los bienes patrimonializados que constituyen el Sistema Patrimonial (bienes culturales y naturales y los ejes que los interconectan y los hacen accesibles), con objeto de preservarlos por ser elementos básicos de la estructura del ámbito, y por su capacidad de articulación y fomento de la identidad socioterritorial.

Al incorporar al paisaje como elemento activo en la política y gestión del patrimonio y en la configuración de entornos de calidad, aseguramos la puesta en valor del patrimonio cultural y la definición de modelos de regeneración que favorecen los procesos identitarios y la modelización de escenarios de futuro que resultan ser eficaces en los procesos de participación ciudadana y en la toma de decisiones en la elaboración del planeamiento, porque para que éstos sean útiles requieren de espacios colectivos de decisión y de procesos de construcción del conocimiento capaces de impulsar modelos de ciudad y territorios más humanizados.

\subsection{Mirada 3: De patrimonios y paisajes: sujetos y objetos en la ( re)producción delespacio}

Otro de los intereses motivadores de los estudios de paisaje ha sido la transformación o "perdida" del patrimonio; un disparador que ha inducido a ensayar posturas que abogan por la conservación o preservación de esos paisajes constituidos en imágenes o referentes icónicos de territorios y sus modos de desarrollo en los que no ha estado ausente la mercantilización como estrategia. Alejados del romanticismo que esa perspectiva podría suponer, interesa ahondar en el paisaje como un patrimonio de construcción permanente en el que se conjugan las valoraciones que han efectuado y/o efectúan los actores que inciden en su producción quienes, en función de su cosmovisión individual y/o colectiva, le atribuyen valores o no y/o proyectan acciones resignificando el proceso de producción continua. El paisaje se muestra así, mediando la comunicación y comprensión de los fenómenos, procesos y actores que pujan en la construcción del territorio. En este sentido, estaría indicando la "forma en que las personas comprenden y se insertan en el mundo material que las rodea" (Zusman, 2008:287). Es aquí donde el paisaje se pone en tensión para comprender el patrimonio territorial, a través de sus usos, disputas y también de resistencias frente las nuevas acciones. Desde esta perspectiva, el paisaje permite asociarle calificaciones en función de categorías que dan cuenta de las conjunciones que las territorialidades señalan a través de sus marcas. Calificaciones que 
enfatizan las diversidades frente a las homogenizaciones, y/o banalizaciones presentes en los paisajes actuales (Muñoz, 2008; Zusman, 2008). Aquí el sistema de patrimonio territorial (Pota, 2006; Pastor, 2008; Feria Toribio, 2010) estaría dando cuentas de las señas de identidad impresas en el territorio y que el paisaje, como categoría analítica, ayudaría a despejar.

En este contexto interesa revisar los paisajes en los que la resiliencia social y comunitaria configura un sistema de patrimonio territorial articulado sobre las estrategias y mecanismos destinados a acceder y hacer uso del agua. A partir de un inventario de bienes y prácticas, espacial y temporalmente localizadas, también de las percepciones y valoraciones que los mismos actores realizan-, se reconoce y caracteriza uno de los paisajes que dan cuentas de los territorios de tierras secas.

En estos contextos se avanza sobre el caso Mendoza, donde el agua para riego es el eje que ha organizado el territorio (Montaña et al., 2005), concentrando en los oasis irrigados los sectores más dinámicos - económicos, sociales políticos- aun a costa de una huella ecológica sumamente alta (Torres, 2010); en las tierras secas no irrigadas el agua es además, el recurso sobre el que se asienta la reproducción social. Del conjunto de dispositivos que los saberes locales han desarrollado para acceder al agua en las tierras secas no irrigadas (Pastor, 2005), sobresalen los pozos jagüel. Concretamente consisten en cavidades construidas para dar acceso a las primeras napas de agua en forma directa, sin la necesidad excluyente de instrumentos mediadores como baldes u otro tipo de recipiente para colectarla o conducirla. Estos pozos permiten que el ganado $-y$, en casos extremos de sequía también los humanos- accedan a los depósitos naturales de agua subterránea (Pastor \& Torres, 2014). La presencia de estos pozos indica no sólo la existencia de agua subterránea relativamente poco profunda allí donde se construyen, sino que estarían señalando el uso del espacio a través del complejo sistema tecnológico para su captación y aprovechamiento al interior de la unidad doméstica de producción (Sahady Villanueva et al, 2011). También, cómo se efectúa ese uso a través de los intercambios y reciprocidades que la organización social propia del territorio en cuestión, propicia y demanda.

Si bien este sistema patrimonial condensa elementos materiales y simbólicos de larga data, también asume los cambios del sistema (Espinosa et al, 2015) e incorpora las nuevas resignificaciones asociadas a esos cambios que conforman las capacidades para sobreponerse física y funcionalmente a las disponibilidades de agua. El sistema de patrimonio territorial efectivamente resulta un "recurso", aunque apenas alcance a colaborar en salvar la brecha en el acceso y uso del patrimonio natural y caracterice las estrategias de resistencia frente a procesos económicos, sociales, incluso políticos de carácter global y/o local.

El paisaje resiliente asume con flexibilidad los desafíos de las dinámicas territoriales a la vez que consolida sus señas de identidad (Sánchez Fuentes et al, 2010); también hablan de éticas territoriales diversas, que con estéticas también diferenciales, tensionan los sistemas de patrimonio territorial. La producción de paisajes en los escenarios latinoamericanos da cuenta de estos fenómenos y es en este contexto, que se plantean nuevos interrogantes para indagar en alcance y potencialidad del paisaje como patrimonio y categoría analítica puede alcanzar para pensar, en palabras de Mitchell (2003; 2008), en paisajes más justos.

\section{Discusión y Reflexiones finales en proceso: desplazamientos eincertidumbres}

Las perspectivas teóricas, casos y escalas, resultados y desafíos pendientes reafirman la pregnancia de la construcción del conocimiento en redes insertas en espacios de cooperación en cuyo contexto se despliegan las articulaciones internodales e interinstitucionales. El tema/problema sobre el que se articula la red que aquí se ha dado cuentas tensiona aún más 
dichas perspectivas, dada la condición de espacio de vacancia en el conocimiento científico particularmente asociado a un territorio sumamente complejo y diverso que se despliega en el espacio latinoamericano. En ese sentido, los documentos internacionales originados en organismos multilaterales de alcance global, así como de otros emanados de instituciones y organizaciones de escalas más restringidas comparten algunos aspectos, aunque los segundos se hacen eco, en gran medida, de los primeros. Si bien existe una gran coincidencia en la base de las perspectivas, perduran matices que, si bien por un lado intentan acotar esa inconmensurabilidad que el paisaje denota, al mismo tiempo, sesgan enfoques que restringirían alcances colisionando con los documentos y posicionamientos más inclusivistas.

Esos mismos desafíos parecieran no haber cuajado aún en una definición taxativa de instrumentos o de lineamientos precisos. De allí la oportunidad para definir un espacio para la exploración teórica e instrumental, que la RIPLa hace suyos como desafío. Los caminos de búsquedas amparados en marcos teóricos también diversos recortan un campo propicio para el renovado encuentro de la construcción del conocimiento en red.

Tres miradas que convergen en dejar de lado -aunque sea por el momento- la estética, lo histórico per se y se afirman en la relación con el mundo, con el ser en el mundo y de allí, con el territorio, los territorios y al mismo tiempo, con las micro geografías, para abarcar la ciudad más allá de lo "urbano" y los cuestionamientos a las perspectivas urbanas desde las resiliencias.

Población, participación, emoción, vivencias, tiempos, son términos e ideas recurrentes que encuadran y matizan las tres miradas a la vez que cuestionan los argumentos sectoriales de los expertos o de las "verdades" consensuadas. Aluden además, a paisajes marcadamente heterogéneos cuya totalidad de sentido se alcanza en esa misma diversidad de tiempos, escalas, procesos y actores.

Tres desplazamientos proponemos aquí, en relación con la construcción del paisaje de la ciudad, de la ciudad y el paisaje.

- La ascensión como mirada ascendente, no contemplativa ni homologada. Pretende captar lo furtivo del instante, visibiliza lo propio y escamotea lo genérico, da una experiencia completa y no busca fijezas. Va más allá de lo visible en procesos de cambio progresivos.

- La acumulación atiende a la imposibilidad de alternativas al régimen del capital. Usa sus términos, pero invoca a la detección de sus límites, de sus campos de tensión, como mirada que formula ciudad como reverso de su forma, pero también territorios y paisajes cuyos patrimonios locales revelan las resiliencias socio-territoriales.

- La espacialización se acoge a la propia condición del espacio: la relación. Trayectos y afectos para un espacio que se extiende más allá de los términos físicos.

Tres claves que permitirían articular la amplitud y dispersión del campo de conocimientos, y accionar la diferencia entre lo que Tapia et al (2012) denominan hiperbólicamente Townscapes y Townscopes. No ya el competitivo marketing urbano, sino la visibilidad amplia de los hábitos, prácticas, deseos y poderes que constituyen el perfil para mostrar la ciudad de hoy, como señalábamos antes, más allá de sus términos físicos. Para insistir en ello, véase el argumento de Besse (2006:80) que aclara:

“[...] no hay paisaje sin la coexistencia del aquí y allí, la coexistencia de lo visible y oculto, que define la abertura sensible y situada al mundo [...] el paisaje es el espacio de los sentimientos, es decir, el foco original de todo encuentro con el mundo". 
Si bien los enfoques y argumentaciones expuestos en este trabajo no son homogéneos, estarían dando cuentas de las rugosidades y texturas que los paisajes latinoamericanos exhiben y que algunas miradas intentan recoger para volver a mirar, para proponer desplazamientos; para, finalmente, volver a revisar ese proceso nunca terminado y siempre renovado que es la producción de paisajes.

\section{Referencias}

Aldred, O. \& Fairclough, G. (2003). Historic landscape characterization: Taking stock of the method. The National HLC Method Review, English Heritage. Recuperado de: http://www.englishheritage.org.uk/publications/hlc-taking-stock-of-the-method/

Atkinson, P., Delamont, S., \& Hammersley, M. (1988). Qualitative research traditions: A British response to Jacob. Review of Educational Research, 58(2), 231-250. https://doi.org/10.3102/00346543058002231

Avendaño Flores, I. (2010). Un recorrido teórico a la territorialidad desde uno de sus ejes: El sentimiento de pertenencia y las identificaciones territoriales. Inter-C-a-mbio, 7(8) 13-35. Recuperado de https://dialnet.unirioja.es/descarga/articulo/5089083.pdf

Bauman, Z. (2005). Comunidad: en busca de seguridad en un mundo hostil. Buenos Aires: Siglo XXI.

Bauman, Z. (2002). Cultura como praxis. Barcelona: Ediciones Paidós I bérica.

Bauman, Z. (2005). I dentidad. Madrid: Editorial Losada.

Baumann, G. (2001). El enigma multicultural. Un replanteamiento de las identidades nacionales, étnicas y religiosas. Barcelona: Ediciones Paidós I bérica.

Bertrand, G. (2008). Un paisaje más profundo. De la epistemología al método. Cuadernos Geográficos, 43, 17-27. Recuperado https://dialnet.unirioja.es/descarga/articulo/3027445.pdf

Bertuzzi, M. L. (2009). La costa del río Paraná: cultura, naturaleza y territorio. Apuntes para su $\begin{array}{lllll}\text { interpretación y } & \text { y } & \text { 22(1), } & \text { 68-81. }\end{array}$ http://www.scielo.org.co/pdf/apun/v22n1/v22n1a06.pdf

Besse, J. M. (2006). Ver a Terra: seis ensaios sobre a paisagem e a geografia. São Paulo: Editora Perspectiva.

Bourdieu, P. (1994). Razones prácticas. Sobre la teoría de la acción. Barcelona: Editorial Anagrama, S.A.

Caballero Sánchez, J. (2012). Los valores paisajísticos. Elementos para la articulación entre teoría e interpretación del paisaje. Cuadernos Geográficos, 51, 245-269.

Campos Reyes, O. (2003). Del paisaje a la ciudad. Revista Bitácora Urbano Territorial, 1(7), 44-52. Recuperado de: http://www. redalyc.org/articulo. oa?id=74810707

Carré, J. y Metailié, J. (2008). De los paisajes de ayer a los paisajes de mañana. Metodología de un Observatorio fotográfico para el análisis de las dinámicas paisajísticas: el valle de Vicdessos, Pirineos de Ariége (Francia). Cuadernos Geográficos, 43, 123-149. 
Carta I beroamericana del Paisaje Cultural. Recomendaciones propuestas en el encuentro de Cartagena de Indias, noviembre de 2012. Recuperado de: https://encuentrospaisajesculturales.wordpress.com/

Clarke, J., Darlington, J., \& Fairclough, G. (Eds.) (2003). Pathways to Europe's Landscape, EPCZ.

Council of Europe (2000). European landscape convention, Florence, European Treaty Series No. 176. Florence, Italy. Recuperado de: http://www.coe.int/t/dg4/cultureheritage/heritage/Landscape/presentationen.asp

Countryside Agency and Scottish Natural Heritage. (2002). Landscape character assessment: Guidance for England and Scotland. Recuperado de: http://www.snh.org.uk/wwo/sharinggoodpractice/cci/.htm

Declaración de Santiago de Cuba sobre los paisajes culturales del Caribe. (2005). Reunión de Expertos sobre los Paisajes Culturales del Caribe. Oficina Regional de Cultura de la Unesco para América Latina y el Caribe, Centro de Patrimonio mundial y Oficina del Conservador de la Ciudad de Santiago de Cuba.

English Heritage and Cornwall County Council, England's Historic Seacapes: Historic Seascape Characterisation (HSC), Truro, 2008.

Espinosa, P., Meulder, B., Alarcón, M., y Pérez, L. (2015). Interacciones de agua y ciudad/Una investigación de urbanismo del paisaje aplicado al caso del río Andalién, Concepción. Revista de Urbanismo, 33, 52-72. https://doi.org/10.5354/0717-5051.2015.36569

Etulain, J. C. y López, I. (2010). La valoración del paisaje cultural como instrumento de intervención territorial. Revista Brasileira de Horticultura Ornamental, 16(1), 1-5. Recuperado de http://132.248.9.34/hevila/Revistabrasileiradehorticulturaornamental/2010/vol16/nol/1.pdf

Fairclough, G. (Ed.). (1999). Historic landscape characterization. London: English Heritage.

Fairclough, G. J., Lambrick, G., \& McNab, A. (Eds.) (1999). Yesterday's landscape, tomorrow's worldThe English Heritage Landscape Project. London: English Heritage.

Feria Toribio, J. (2010). Patrimonio territorial y desarrollo sostenible: un estudio comparativo en Iberoamérica y España. Estudios Geográficos, 71(268), 129-159. https://doi.org/10.3989/estgeogr.0472

Ferrari, M. y Paterlini de Koch, O. (2013). La conservación de la autenticidad y la integridad del paisaje cultural como bases de los procesos de gestión. Revista PH. Recuperado de: http://www.iaph.es/revistaph/index.php/revistaph/article/view/3407\#.WbR0SOrygnU

Gadamer, H.-G. (1999). Gesammelte Werke 1. Hermeneutik I. Tübingen, Mohr. Trad. Cast. (1977, 1999). Verdad y Método I, Salamanca, Sígueme.

Gadamer, H.-G. (1999) Gesammelte Werke 2. Hermeneutik II. Tübingen, Mohr. Trad. Cast. (1992). Verdad y Método II, Salamanca, Sígueme.

Gandolfi, C. (2009). Els instruments de protecció i valorització del paisatge a Itàlia: el cas de la Toscana. En Nogué I Font, J., Puigbert, L. Y Bretcha, G (Eds.), Ordenació y gestió del paisatge a Europa (169-185). Olot: Observatori del Paisatge de Catalunya. 
Hall, S. (2003). Introducción: ¿Quién necesita "identidad"? En Hall, Stuard y Paul du Gay (Eds.), Cuestiones de identidad cultural (13-39). Buenos Aires: Amorrortu.

Hammersley, M. y Atkinson, P. (1983). Etnografía. Métodos de investigación. Barcelona: Paidós.

Harvey, D. (1990). La condición de la posmodernidad: investigación sobre los orígenes del cambio cultural. Buenos Aires: Amorrortu Editores.

Harvey, D. (1969). Explanations in Geography. London: Arnold.

Jiménez Olivencia, Y. (2008). La convención europea del paisaje. Desarrollos prácticos. Cuadernos Geográficos, 43, 1-394. Recuperado de http://www.ugr.es/ cuadgeo/docs/revistas/043.pdf

Jociles Rubio, M. I. (1999). Las técnicas de investigación en antropología y proceso etnográfico. Gazeta de Antropología, 15(1), 26.

Junta de Andalucía. (2006). Plan de Ordenación Territorial de Andalucía. Sevilla, Consejería de Obras Públicas y Transportes. Recuperado de http://www.juntadeandalucia.es/obraspublicasyvivienda

Lambrick, G., Hind, J., \& Wain, I. (2013). Historic landscape Characterization in I reland: Best practice guidance. An Chomhairle Oidhreachta/The Heritage Council.

Latour, B. (2004). ¿Por qué se ha quedado la crítica sin energía? De los asuntos de hecho a las cuestiones de preocupación convergencia. Revista de Ciencias Sociales, 11. Recuperado de http://www.redalyc.org/articulo.oa?id $=10503502$

Latour, B. (2005). Reassembling the social: An introduction to actor-network theory. Oxford: Oxford University Press.

Maderuelo, J. (2010). El paisaje urbano. Estudios Geográficos, 71(269), 575-600. https://doi.org/10.3989/estgeogr.201019

Marchionni, F., Moreno, S., D’Amico, P., Accorinti, C., Esteves, M., Sales, R., ... y Pessolano, D. (2014). Introducción. Territorio y tierras secas: reflexiones teóricas desde miradas interdisciplinarias. En L. Torres, E. Abraham, y G. Pastor (Coords.), Una ventana sobre el territorio: herramientas teóricas para comprender las tierras secas (pp. 11-29). Mendoza: Editorial EDIUNC.

Martignoni, J. (2008). Latinscapes. El paisaje como materia prima. Barcelona: Ed. Gustavo Gili.

Martínez de Pisón, E. (007). Paisaje, cultura y territorio. En J. Nogué (Ed.), La construcción social del paisaje (331-337). Madrid: Ed. Biblioteca Nueva.

Martínez de Pisón, E. (1997). El paisaje, patrimonio cultural. Revista de Occidente, 194-195, 37-49.

Massey, D. (2006). For space. London: SAGE Publications.

Massey, D. (2005). La filosofía y la política de la espacialidad: algunas consideraciones. En L. Arfuch, Leonor (Comp.), Pensar este tiempo: espacios, afectos, pertenencias (101-128). Buenos Aires: Editorial Paidós.

Mitchell, D. (2007). Muerte entre la abundancia: los paisajes como sistemas de reproducción social. En J. Nogué (Ed.), La construcción social del paisaje. Madrid: Biblioteca Nueva. 
Mitchell, D. (2003). Cultural landscapes: Just landscapes or landscapes of justice? Progress in Human Geography December, 27, 787-796.

Mitchell, N., Ro" ssler, M., \& Tricaud, P. (2009). World heritage cultural landscapes: A handbook for conservation and management. Paris: Unesco.

Montaña, E., L. Torres, E., Abraham, E., Torres, y Pastor, G. (2005). Los espacios invisibles. Subordinación, marginalidad y exclusión de los territorios no irrigados en las tierras secas de Mendoza, Argentina. Región y Sociedad, México, 32, 3-32.

Muñoz, F. (2008). Urbanalización. Paisajes comunes, lugares globales. Barcelona: Ed. Gustavo Gili.

Murcia, N. (2001). La complementariedad como posibilidad en la estructuración de diseños de investigación cualitativa. Cinta de Moebio, Revista de Epistemología de Ciencias Sociales, 12, 194204. Recuperado de http://www. revistas. uchile.cl/index. php/CDM/article/view/26293/27593

National Park Service. (2002). The Secretary of the Interiors Standards for the Treatment of Historic Properties with Guidelines for the Treatment of Cultural Landscapes. Recuperado de https://www.nps.gov/tps/standards/fourtreatments/landscapeguidelines/preservation_planning.htm

Observatori Del Paisatge (Coord) (2010). Comarques Gironines. Catàleg de paisatge. Girona: Generalitat de Catalunya. Departament de Política Territorial i Obres Públiques.

Observatori Del Paisatge (Coord) (2006). Prototipus de catàleg de paisatge. Document de referència per als grups de treball (edició revisada) Bases conceptuals, metodològiques i procedimentals per elaborar els catàlegs de paisatge de Catalunya, Olot i Barcelona.

Ojeda, J. y Cano, N. (2009). El paisaje, memoria de los territorios. XVII Congreso de Estudios Vascos. Cataluña: Estudios Vascos.

Paniza Cabrera, A. (2008). 23 Sesión del Permanent European Conference for the Study of the Rural Landscapes. 1-5 de septiembre de 2008. Lisboa-Óbidos. Cuadernos Geográficos, 43, 367-369.

Pastor, G., Marchionni, F., Estévez, M., y Sales, R. (2014). Intersecciones de paisaje. En L. Torres, E. Abraham, y G. Pastor (Coords.), Una ventana sobre el territorio: herramientas teóricas para comprender las tierras secas (pp. 117-121). Editorial EDIUNC.

Pastor, G. (2008). La construcción del paisaje cultural en la ordenación del espacio turístico. El Valle de Tafí. Recuperado de: http://fondosdigitales.us.es/tesis/tesis/1795/la-construccion-delpaisajecultural-en-la-ordenacion-del-espacio-turistico-el-valle-de-tafi/

Pastor, G. y Torres, L. (2014). Tecnologías tradicionales de uso del agua en tierras secas de Mendoza (Argentina). Zonas Áridas, 15(2), 290-301.

Pérez Bustamente, L. y Parra Ponce, C. (2004). Paisajes culturales: el parque patrimonial como instrumento de revalorización y revitalización del territorio. Theoria, 13, 9-24. Recuperado de: http://www.ubiobio.cl/theoria/v/v13/1.pdf

Plan de Ordenación del Territorio de Andalucía (POTA). Boletín Oficial de la Junta de Andalucía no 136, de 17 de julio de $2006 . \quad$ Recuperado de: http://www.juntadeandalucia.es/medioambiente/site/portalweb/menuitem. 7

Pressouyre, L. (1996). The World Heritage Convention, twenty years later. Paris: Unesco. 
Riesco Chueca, P., Zoido Naranjo, F., y Phillips, A. (2008). Una opinión destacada sobre el convenio europeo del paisaje. Cuadernos Geográficos, 43, 351.

Ríos, M., Rössler, M., y Lepeigné-Cobo, A. M. (Eds.) (2000). Paisajes culturales en Mesoamérica. Reunión de Expertos, Memoria. 27 al 30 de septiembre de 2000. Unesco.

Sabaté Bel, J. y Vera Galván, J. (2008). Aspectos varios de la implementación de la Convención Europea de Paisaje en el Plan Territorial Especial de Ordenación de Paisaje de Tenerife. Cuadernos Geográficos, 43, 51-67.

Sahady Villanueva, A., Bravo Sánchez, J., y Quilodrán Rubio, C. (2011). Las azudas de Larmahue: una singular manifestación del ingenio humano para regar cultivos en tierras de secano. Revista de Urbanismo, 25, 6-25. https://doi.org/10.5354/0717-5051.2011.18316

Sánchez Fuentes, D., Pastor, G., Montaña, E., y Navarrete, S. (2010). Paisajes culturales intersticiales de los espacios turísticos al pie de los andes. ¿Territorios de exclusión o cohesión? CONAMA 10 Congreso Nacional de Medio Ambiente. Madrid.

Sankey, D. (2008). A review of the Clare historic landscape characterization as a component of the Clare landscape character assessment. Ireland: Heritage Council.

Santos, M. (1994). O retorno do território. En M. Santos, A. de Souza, y M. L. Silveira (Eds.), Territorio: Globalizaçao e fragmentação (pp. 15-20). São Paulo: Hucitec.

Tapia, C., Rodrigues Alves, M., y Saliba Rizek, C. (2012). TownScapes/TownScopes: Del paisaje monumental al hodológico. Actas 54th International Congress of Americanists (pp.355-356). Universität Wien.

The George Wright Forum. (2000). The Journal of the George Wright Society. Special issue: Landscape stewardship. New directions in conservation of nature and culture, $17(1)$.

The Latin American Landscape Initiative (Lali). (2012). La Iniciativa Latinoamericana del Paisaje. Composed in Colombia the 30th of August, 2012, in Spanish, English, and Portuguese and, being three equally authentic texts, in a single draft that will be deposited in the Latin American Landscape Observatory. Recuperado de: http://iflaonline.org/wpcontent/uploads/2014/12/120910-LALI_EN_Final.pdf

Torres, L. (2010). Claroscuros del desarrollo sustentable y la lucha contra la desertificación: las racionalidades económicas en el ojo de la tormenta: Estudio de caso con productores caprinos de tierras secas [Mendoza, Argentina]. Mundo Agrario, 11(21).

Tress, B., Tress, G., Décamps, H., \& d'Hauteserre, A. (2001). Bridging human and natural sciences in landscape research. Landscape and Urban Planning, 57(3-4), 137-141. https://doi.org/10.1016/s0169-2046(01)00199-2

Tress, B. \& Tress, G. (2001). Capitalising on multiplicity: A transdisciplinary systems approach to landscape research. Landscape and Urban Planning, 57(3-4), 143-157. https://doi.org/10.1016/s0169-2046(01)00200-6

Turner, S. \& Crow, J. (2010). Unlocking historic landscapes in the Eastern Mediterranean: Two pilot studies using Historic Landscape Characterization. Antiquity, 84(323), 216-229. https://doi.org/10.1017/s0003598x00099889 
Unesco (2002). World Heritage Centre: Cultural Landscapes: The Challenges of Conservation. Proceedings of the conference, World Heritage 2002, Shared Legacy, Common Responsibility. Recuperado de http://unesdoc.unesco.org/images/0013/001329/132988e.pdf

Zusman, P. (2008). Perspectivas críticas del paisaje en la cultura contemporánea. En J. Nogué (Ed, El paisaje en la cultura contemporánea. Madrid: Biblioteca Nueva. 